\title{
Serum anti-Müllerian hormone levels and phenotypes of polycystic ovary syndrome
}

\section{Hye Ok Kim}

Department of Obstetrics and Gynecology, Cheil General Hospital, Kwandong University College of Medicine, Seoul, Korea

\section{Reply:}

We recently published an original article entitled "Can high serum Anti-Müllerian hormone (AMH) levels predict the phenotypes of polycystic ovary syndrome (PCOS) and metabolic disturbances in PCOS patients?" [1]. There are numerous reports on high serum AMH levels in patients with PCOS, and their serum AMH levels are much variable. We were curious about the possibility that high serum $\mathrm{AMH}$ levels are correlated with the phenotypes of PCOS and metabolic derangement. We did not find any significant difference according to the phenotypes of PCOS in the non-obese group.

The correspondents pointed out that our result is different from a recent report from Sahmay et al. [2]. The study of Sahmay et al. [2] was a cross-sectional retrospective study and included 251 women with PCOS. They concluded that AMH levels seem to play a diagnostic role in determining the severity of $\mathrm{PCOS}$. There are differences in this study population, who had over $75 \%$ hyperandrogenism $(\mathrm{HA})$ and had a similar body mass index (BMI) among the groups. Our study group showed a relatively low percentage of HA $(36 \%, 59 / 175)$ and significantly higher BMI in the PCOS patients who had 3 diagnostic criteria (anovulation+HA+polycystic morphology). PCOS women without HA are more common in Korea and are less likely to have metabolic dysfunction, insulin resistance, and elevated blood pressure [3]. PCOS without HA could be a mild phenotype of PCOS [3]. In another study, it was reported that Chinese women with PCOS showed lower rates of HA, hirsutism, obesity, and insulin resistance [4]. Furthermore, obese women have lower AMH levels compared to non-obese women [5]. Recently, it has been recommended that the follicle number per ovary for the diagnosis of polycystic ovary morphology be set at $\geq 25$ [6]. The thresholds used to define follicle excess, particularly in diverse populations must be reconsidered. We suggest that ethnicity might contribute to variation. We value the comments of the correspondents and plan to perform a larger scale study to clarify these results.

\section{Conflict of interest}

No potential conflict of interest relevant to this article was reported.

\section{References}

1. Hwang Yl, Sung NY, Koo HS, Cha SH, Park CW, Kim JY, et al. Can high serum anti-Mullerian hormone levels predict the phenotypes of polycystic ovary syndrome (PCOS) and metabolic disturbances in PCOS patients? Clin Exp Reprod Med 2013;40:13540.

2. Sahmay S, Atakul N, Oncul M, Tuten A, Aydogan B, Seyisoglu H. Serum anti-Mullerian hormone levels in the main phenotypes of polycystic ovary syndrome. Eur J Obstet Gynecol Reprod Biol 2013;170:157-61.

3. Chae SJ, Kim JJ, Choi YM, Hwang KR, Jee BC, Ku SY, et al. Clinical and biochemical characteristics of polycystic ovary syndrome in Korean women. Hum Reprod 2008;23:1924-31.

4. Zhang HY, Guo CX, Zhu FF, Qu PP, Lin WJ, Xiong J. Clinical characteristics, metabolic features, and phenotype of Chinese women with polycystic ovary syndrome: a large-scale case-control study. Arch Gynecol Obstet 2013;287:525-31.

5. Freeman EW, Gracia CR, Sammel MD, Lin H, Lim LC, Strauss JF $3 \mathrm{rd}$. Association of anti-mullerian hormone levels with obesity in late reproductive-age women. Fertil Steril 2007;87:101-6.

6. Dewailly D, Lujan ME, Carmina E, Cedars MI, Laven J, Norman RJ, et al. Definition and significance of polycystic ovarian morphology: a task force report from the Androgen Excess and Polycystic Ovary Syndrome Society. Hum Reprod Update 2013 Dec 16 [Epub]. http://doi.dx.org/10.1093/humupd/dmt061.

Hye Ok Kim

Department of Obstetrics and Gynecology, Cheil General Hospital, Kwandong University College of Medicine, Seoul, Korea E-mail: ok58163@hanmail.net Received:Dec 26, 2013

This is an Open Access article distributed under the terms of the Creative Commons Attribution Non-Commercial License (http://creativecommons.org/licenses/by-nc/3.0/) which permits unrestricted non-commercial use, distribution, and reproduction in any medium, provided the original work is properly cited. 